\title{
The Effect of Meteorological Factors on the Population Dynamics of Melon fly, Bactrocera cucurbitae (Coq.) (Diptera: Tephritidae) in the foot hills of Himalaya
}

\author{
NRIPENDRA LASKAR; HIRAK CHATTERJEE * \\ Department of Agricultural Entomology, Uttar Banga Krishi Viswavidyalaya, Pundibari, Cooch Behar, West Bengal, India-736165 \\ E-mail ID: nripendralaskar@yahoo.co.in \\ * Department of Plant Protection, Palli Siksha Bhavana, Viswa-Bharati, Santiniketan, Bolpur, West Bengal, India
}

\begin{abstract}
An exhaustive approach had been undertaken to investigate the incidental pattern of Bactrocera cucurbitae (Coq.) (Diptera : Tephritidae) round the year with a view to formulate a sustainable management technique against the pest. Significant variation in occurrence of the pest was recorded during the period of investigation. Trapping of male melon fly was started from 01.10 .2006 and continued up to 30.09 .2008 by using sex attractant, Cuelure. During warm and rainy months (June, July, August, at $25-37^{\circ} \mathrm{C}$ ) the flies were more active as compared to that of dry and winter (December, January, February $8-23^{\circ} \mathrm{C}$ ) months. Significant positive correlation ( $r)$ of fly incidence was noted with minimum $(r=+0.7596)$ and maximum temperature $(r=+0.7376)$, whereas temperature gradient correlated negatively $(r=-0.4789)$ with fly incidence. Negative correlation of fly incidence was also recorded with maximum humidity $(\mathrm{r}=-0.4249)$ and humidity gradient $(\mathrm{r}=-0.5481)$ and positive $(\mathrm{r}=+0.4366)$ with the minimum. Rainfall and sunshine hour per day showed positive $(r=+0.4367)$ and negative $(r=-0.3123)$ correlation with the fly incidence respectively. Regression equations of fly incidence with all the meteorological parameters were also determined. Results of the present investigation may be utilized in chalking out sustainable pest management strategy in the agro-ecological system under consideration. @ JASEM
\end{abstract}

Fruit flies are important pests of fruits, vegetables and other ornamental plants (Bharathi et al., 2004). The melon fruit fly, Bactrocera cucurbitae (Coq.) is a serious pest of a variety of vegetables especially in snakegourd, Trichosanthes anguina L. found in India (Kapoor, 1993). Extend of yield loss caused by the pest to cucurbitaceous vegetables ranging from 30$100 \%$ depending upon cucurbit species and the season in different parts of the world as noted by Dhillon et el., (2005). It is very much difficult to manage the pest simply through the application of chemical pesticides due to their peculiar biological features. Again, it is also established that before developing insect pest management programme for a specific agro-ecosystem, it is necessary to have basic information on the incidence of the pest in relation to weather parameters which help in determining appropriate time of action and suitable method of control. Monitoring pest population round the year is one of the most important basic information in formulating IPM concept for sustainable agriculture. The discovery of a number of compounds strongly attractive to male fruit flies (Tephritidae) has suggested the possible significance of male attractants (Mahmood et al., 2002). It has been estimated that each male fly removed from the wild fly population by an attractant would represent one unmated female (Ripley and Hepburn, 1935) and for decades, these olfactory attractants have been the basis of tephritid detection, monitoring and control (Jang and Light, 1996). The Cuelure traps have been reported to attract Bactrocera cucurbitae males and this sex attractant is also more effective than food lure (Pawar et al., 1991, Liu and Lin, 1993 and Zaman, 1995).

Keeping in view the known efficacy of Cuelure as a sex attractant, it become highly justifiable to study the population fluctuation of melon fly, Bactrocera cucurbitae male round the year through the use of Cuelure and influence of abiotic parameters such as temperature (minimum, maximum and gradient), relative humidity (minimum, maximum and gradient), rainfall and total sunshine hour per day on its capture.

\section{MATERIALS AND METHODS}

Three Cuelure traps manufactured by Ganesh Biocontrol Systems, Gujrat, India, were hanged at about six feet above the ground level at three places in the pumpkin field grown successively round the year. Each trap was treated as a replication. Cuelure impregnated "Melon block" was there, one in each trap. The study was conducted at the Instructional Farm, Uttar Banga Krishi Viswavidyalaya, Pundibari, Cooch Behar, West Bengal, India $\left(26^{\circ} 19^{\prime} \mathrm{N}\right.$ latitude and $89^{\circ} 23^{\prime} \mathrm{E}$ longitude at an altitude of $43 \mathrm{~m}$ above the MSL). The blocks were replenished at monthly interval and the trapped flies were removed and counted every week starting from 01.10.2006 to 30.09.2007 and again from 01.10.2007 to 30.09.2008. Mean number of flies caught per trap per day were determined every year and average of both the years of study worked out. The observation thus obtained were correlated with the meteorological parameters like temperature (minimum, maximum and gradient), humidity (minimum, maximum and gradient), rainfall and total sunshine hour per day. Regression equation in respective cases was also determined. The meteorological observations were collected from the Meteorological Observatory, Central Tobacco Research Institute (CTRI), Indian Council of Agricultural Research (ICAR), Dinhata, Cooch Behar, West Bengal.

\footnotetext{
* E-mail ID: nripendralaskar@yahoo.co.in
} 
The Effect of Meteorological Factors.....

\section{RESULTS AND DISCUSSION}

The population fluctuation of melon fly in different seasons of the year trapped by using Cuelure traps has been presented in table-1. It appeared from the presentation that during 2006-07, daily catch of the fly in trap varied from 0.00 to 39.33 , the maximum being observed in $25^{\text {th }}$ standard week. No flies were found to be trapped during $49^{\text {th }}, 50^{\text {th }}, 2^{\text {nd }}, 3^{\text {rd }}, 5^{\text {th }}, 6^{\text {th }}$ standard weeks. It was further noted that from $45^{\text {th }}$ to $6^{\text {th }}$ standard weeks activity of the fly was minimum as reflected from the trap catch (0.00 to 4.67).

Table-1: Seasonal fluctuation of melon fruit fly, Bactrocera cucurbitae (Coq.)

\begin{tabular}{|c|c|c|c|}
\hline \multirow[t]{2}{*}{$\begin{array}{c}\text { Standard } \\
\text { weeks }\end{array}$} & \multicolumn{2}{|c|}{$\begin{array}{c}\text { Mean number of fruit flies caught } \\
\text { per trap/day (Average } \pm \text { S.D.) }\end{array}$} & \multirow[t]{2}{*}{ Mean } \\
\hline & $2006-07$ & $2007-08$ & \\
\hline 1 & $0.67 \pm 1.15$ & $0.00 \pm 0.00$ & $0.34(0.92)$ \\
\hline 2 & $0.00 \pm 0.00$ & $0.00 \pm 0.00$ & $0.00(0.71)$ \\
\hline 3 & $0.00 \pm 0.00$ & $0.67 \pm 0.58$ & $0.34(0.92)$ \\
\hline 4 & $0.67 \pm 1.15$ & $0.00 \pm 0.00$ & $0.34(0.92)$ \\
\hline 5 & $0.00 \pm 0.00$ & $0.00 \pm 0.00$ & $0.00(0.71)$ \\
\hline 6 & $0.00 \pm 0.00$ & $2.33 \pm 2.52$ & $1.17(1.29)$ \\
\hline 7 & $4.33 \pm 2.08$ & $0.00 \pm 0.00$ & $2.17(1.63)$ \\
\hline 8 & $6.67 \pm 3.05$ & $12.67 \pm 5.13$ & $9.67(3.19)$ \\
\hline 9 & $10.67 \pm 4.16$ & $8.33 \pm 2.52$ & $9.50(3.16)$ \\
\hline 10 & $19.33 \pm 4.51$ & $17.67 \pm 7.51$ & $18.50(4.36)$ \\
\hline 11 & $24.33 \pm 3.06$ & $6.33 \pm 2.52$ & $15.33(3.98)$ \\
\hline 12 & $26.67 \pm 4.51$ & $15.00 \pm 4.58$ & $20.84(4.62)$ \\
\hline 13 & $31.33 \pm 7.51$ & $11.33 \pm 4.16$ & $21.33(4.67)$ \\
\hline 14 & $26.00 \pm 6.56$ & $6.67 \pm 2.52$ & $16.34(4.10)$ \\
\hline 15 & $28.67 \pm 4.51$ & $0.67 \pm 1.15$ & $14.67(3.89)$ \\
\hline 16 & $27.00 \pm 8.54$ & $19.33 \pm 4.51$ & $23.17(4.87)$ \\
\hline 17 & $35.67 \pm 8.02$ & $21.67 \pm 6.66$ & $28.67(5.40)$ \\
\hline 18 & $25.67 \pm 6.66$ & $8.33 \pm 3.06$ & $17.00(4.18)$ \\
\hline 19 & $34.33 \pm 10.79$ & $9.33 \pm 2.52$ & $21.83(4.73)$ \\
\hline 20 & $34.67 \pm 8.50$ & $14.67 \pm 6.03$ & $24.67(5.02)$ \\
\hline 21 & $37.00 \pm 8.00$ & $12.33 \pm 4.51$ & $24.67(5.02)$ \\
\hline 22 & $38.33 \pm 7.09$ & $7.67 \pm 3.51$ & $23.00(4.85)$ \\
\hline 23 & $31.33 \pm 4.51$ & $25.33 \pm 6.03$ & $28.33(5.37)$ \\
\hline 24 & $36.33 \pm 10.97$ & $14.67 \pm 3.51$ & $25.50(5.10)$ \\
\hline 25 & $39.33 \pm 9.07$ & $19.33 \pm 5.86$ & $29.33(5.46)$ \\
\hline 26 & $34.00 \pm 6.00$ & $12.33 \pm 4.51$ & $23.17(4.87)$ \\
\hline
\end{tabular}

\begin{tabular}{|c|c|c|c|}
\hline 27 & $31.33 \pm 9.07$ & $24.33 \pm 9.02$ & $27.83(5.32)$ \\
\hline 28 & $30.00 \pm 5.57$ & $22.67 \pm 4.51$ & $26.34(5.18)$ \\
\hline 29 & $13.67 \pm 4.16$ & $16.67 \pm 5.13$ & $15.17(3.96)$ \\
\hline 30 & $27.67 \pm 4.03$ & $21.33 \pm 5.69$ & $24.50(5.00)$ \\
\hline 31 & $29.33 \pm 5.13$ & $18.67 \pm 7.23$ & $24.00(4.95)$ \\
\hline 32 & $30.33 \pm 9.29$ & $22.33 \pm 7.37$ & $26.33(5.18)$ \\
\hline 33 & $19.33 \pm 7.57$ & $20.67 \pm 7.57$ & $20.00(4.53)$ \\
\hline 34 & $29.67 \pm 5.03$ & $12.33 \pm 3.51$ & $21.00(4.64)$ \\
\hline 35 & $27.33 \pm 7.57$ & $9.67 \pm 3.79$ & $18.50(4.36)$ \\
\hline 36 & $26.00 \pm 6.56$ & $5.67 \pm 2.08$ & $15.84(4.04)$ \\
\hline 37 & $28.33 \pm 8.08$ & $10.33 \pm 4.73$ & $19.33(4.45)$ \\
\hline 38 & $18.33 \pm 4.51$ & $8.67 \pm 2.52$ & $13.50(3.74)$ \\
\hline 39 & $8.67 \pm 2.52$ & $12.33 \pm 4.73$ & $10.50(3.32)$ \\
\hline 40 & $10.00 \pm 3.60$ & $14.67 \pm 4.51$ & $12.34(3.58)$ \\
\hline 41 & $9.33 \pm 1.53$ & $8.33 \pm 2.52$ & $8.83(3.05)$ \\
\hline 42 & $7.33 \pm 3.21$ & $5.67 \pm 2.52$ & $6.50(2.65)$ \\
\hline 43 & $11.33 \pm 3.06$ & $4.33 \pm 2.31$ & $7.83(2.89)$ \\
\hline 44 & $6.67 \pm 2.08$ & $0.00 \pm 0.00$ & $3.34(1.96)$ \\
\hline 45 & $3.67 \pm 2.08$ & $0.00 \pm 0.00$ & $1.84(1.53)$ \\
\hline 46 & $4.67 \pm 2.08$ & $0.33 \pm 0.58$ & $2.50(1.73)$ \\
\hline 47 & $1.33 \pm 1.15$ & $0.00 \pm 0.00$ & $0.67(1.08)$ \\
\hline 48 & $1.00 \pm 1.00$ & $1.33 \pm 1.15$ & $1.17(1.29)$ \\
\hline 49 & $0.00 \pm 0.00$ & $0.00 \pm 0.00$ & $0.00(0.71)$ \\
\hline 50 & $0.00 \pm 0.00$ & $0.00 \pm 0.00$ & $0.00(0.71)$ \\
\hline 51 & $0.33 \pm 0.58$ & $0.33 \pm 0.58$ & $0.33(0.91)$ \\
\hline 52 & $0.67 \pm 0.58$ & $0.00 \pm 0.00$ & $0.34(0.92)$ \\
\hline & & & \\
\hline
\end{tabular}

After $7^{\text {th }}$ standard weeks fly population starts increasing and attained its peak during $20^{\text {th }}$ to $25^{\text {th }}$ standard weeks (31.33 to 39.33). However, the fly catch was recorded lower during the investigation year 2007-08 as compared to that of 2006-07 being maximum (25.33 flies trapped/trap/day) in $23^{\text {rd }}$ standard weeks. Zero population were recorded in $44^{\text {th }}, 45^{\text {th }}, 47^{\text {th }}, 49^{\text {th }}, 50^{\text {th }}, 52^{\text {nd }}, 1^{\text {st }}, 2^{\text {nd }}, 4^{\text {th }}, 5^{\text {th }}$ and $7^{\text {th }}$ standard weeks during 2007-08. In the second year of study, activity of the fly found minimum during $44^{\text {th }}$ to $7^{\text {th }}$ standard week $(0.00$ to 2.33$)$. Thereafter the incidence become increased and reached maximum (29.33 flies trapped/trap/day) at $25^{\text {th }}$ standard week. The mean incidence obtained from two consecutive years of study also revealed the same trend.

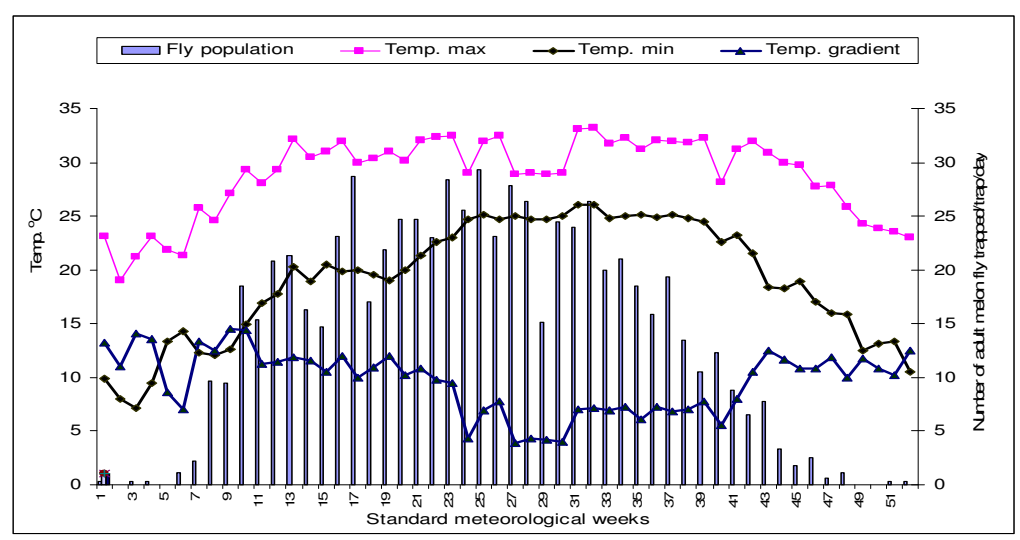

Fig-1: Influence of temperature on the incidence of melon fly, Bactrocera cucurbitae (Coq.)

It appeared from the analysis of Cuelure capture data that all the meteorological parameters contribute significantly toward increasing or decreasing melon fly population. The numerical values of correlation 
The Effect of Meteorological Factors.....

co-efficient and respective regression equations have been presented in table-2. From the presentation it has been found that the mean maximum, minimum temperature showed positive and significant correlation $(\mathrm{r}=+0.7376$ and +0.7596 respectively) with the fruit fly catch per trap per day. However, temperature gradient correlated negatively $(\mathrm{r}=$ 0.4789 ) with the fly population. Relative humidity (minimum, maximum and gradient) influenced fruit fly population variably. Maximum and gradient in relative humidity negatively correlated $(r=-0.4249$ and -0.5481 respectively) with the fly catch, whereas minimum relative humidity showed positive correlation $(\mathrm{r}=+0.4366)$. Rainfall inflicted positive impact on the fly incidence that showed positive correlation $(r=+0.4367)$ with the fly catch per trap i.e. more the rainfall, higher will be the fly catch per trap per day. On the other hand, insignificant negative influence $(r=-0.3123)$ of total sunshine hour per day on adult melon fly incidence was revealed in the study.

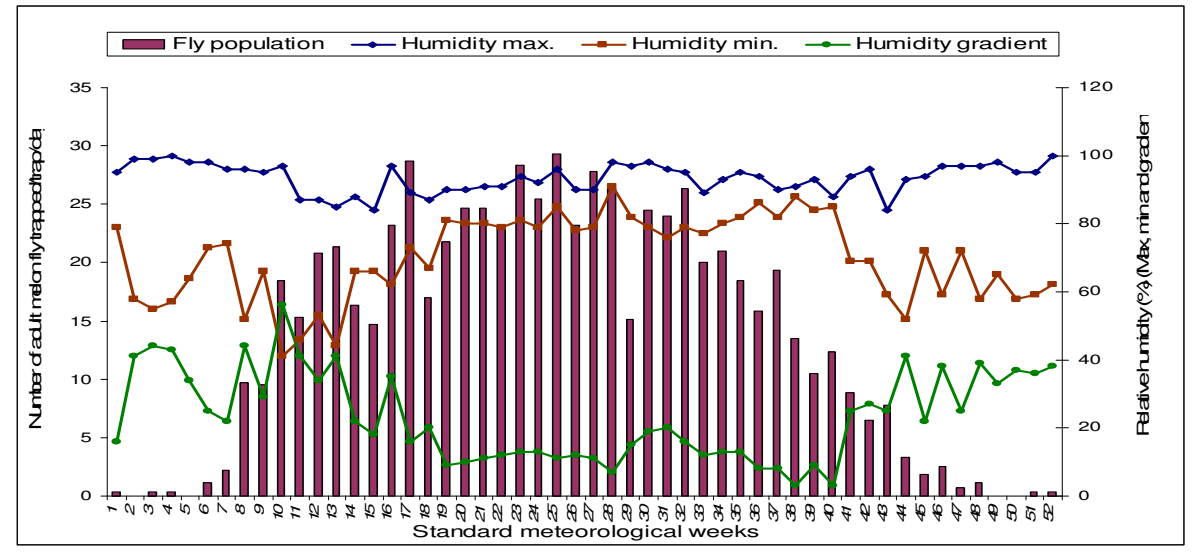

Fig-2: Influence of relative humidity (\%) on the incidence of melon fly, Bactrocera cucurbitae (Coq.)

Peak population of melon fly was earlier recorded during summer followed by winter season (Banerji et al., 2005). Marked decrease in fly population has taken place during winter months of the year (Tanaka and Nagashimad, 1987). Some workers noted peak population of the fly during April-May i.e. around $18^{\text {th }}-20^{\text {th }}$ standard weeks (Virakthamath and Babu, 2004; Patnaik et al., 2004). Fruit infestation by melon fly on little gourd recorded throughout the year starting from the month of February reaching peak during $3^{\text {rd }}$ week of March but negligible infestation during December-January (Patel and Patel, 1996). However, fruit fly, Dacus ciliatus activity found peak during October to May in Pretoria, while population of $D$. ciliatus starts to begin in October and reached to its peak at the end of November in Nigeria as noted by Bot, (1965) and Matanmi, (1979). In a study conducted in Pakistan, population peak of the genus Bactrocera appeared in July-August and declining was observed in October depending on the host fruit maturity, temperature and rainfall (Mahmood and Mishkatullah, 2007). It has also been detected that the flies congregate under leaves of plants in winter, become active when warm weather approaches (Nair, 1995). Fluctuation in population of the fly may be due to prevalence of congenial environmental conditions and/or fruiting and flowering time of the hosts concerned.

All abiotic factors contribute significantly toward increasing or decreasing fruit flies trapped with the help of sex attractant. Positive and highly significant correlation of Dacus zonatus incidence with minimum and maximum temperature was recorded earlier by Lui and Yeh, (1982). The number of fruit flies captured with cuelure baited traps correlated positively with all three abiotic factors, i.e. temperature, humidity and rainfall (Hasyim et al., 2008). Similar observation with regard to influence of meteorological parameters on the incidence of melon fly was also claimed earlier by several workers (Mahmood et al.,2002, Gupta and Bhatia, 2000; Shukla and Prasad, 1985 and Su, 1984). The fly incidence in relation to environmental temperature has been depicted graphically in Fig-1. 
The Effect of Meteorological Factors.....

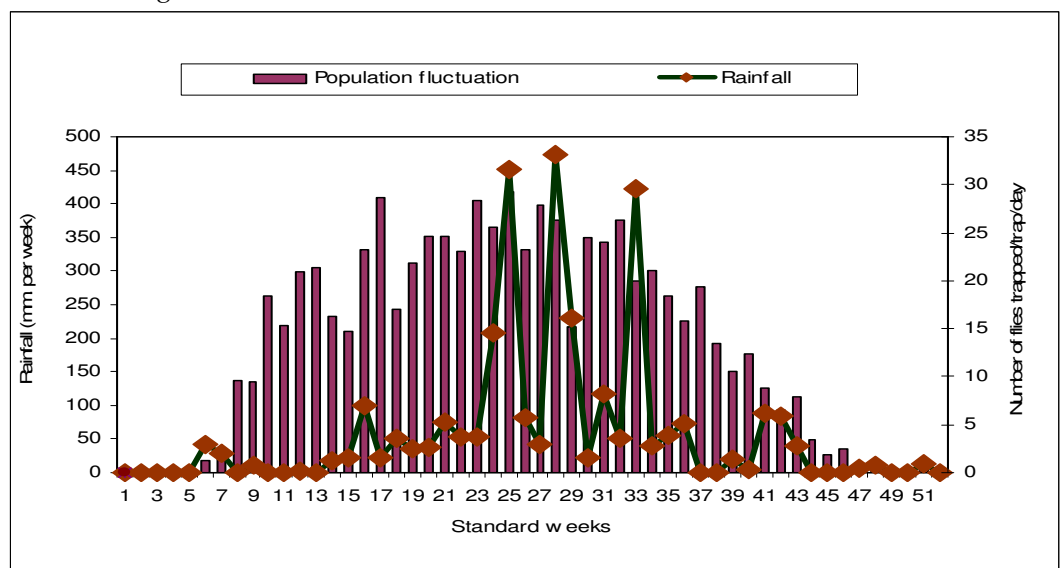

Fig-3: Influence of rainfall on the incidence of melon fly, Bactrocera cucurbitae (Coq.)

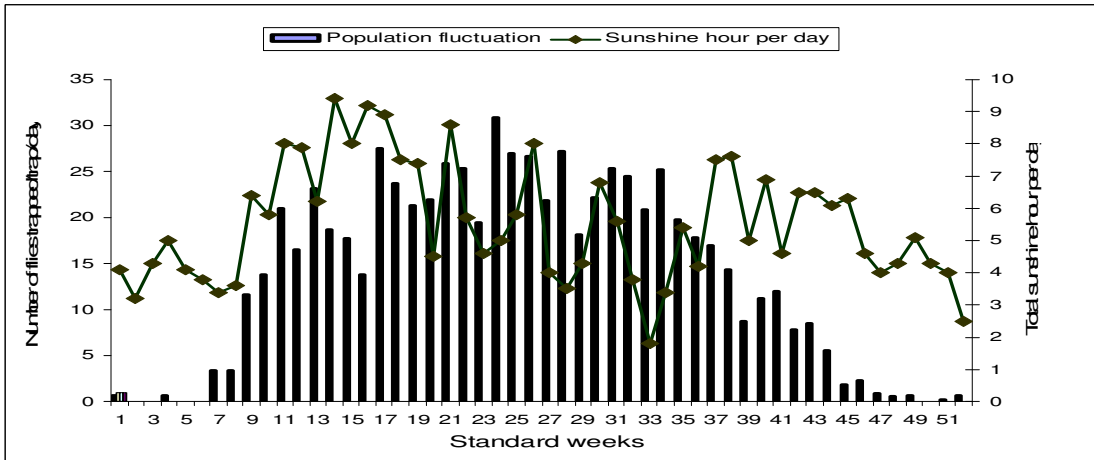

Fig-4: Influence of sunshine hour on the incidence of melon fly, Bactrocera cucurbitae (Coq.)

Negative correlation between fruit flies trapped per trap per day and relative humidity, positive and significant correlation between rainfall and fly activity were observed by earlier workers (Shukla and Prasad, 1985, Su, 1984). However, the influence of minimum humidity as found in the present investigation contradicted with the results of earlier findings. This deviation may be due to variation in agro-ecological system as well as cropping pattern of the experimental location. The fly incidence in relation to relative humidity of the environment graphically depicted in Fig-2.

Table-2: Correlation co-efficient and regression equation between meteorological

parameters and melon fly incidence.
\begin{tabular}{|c|c|c|c|}
\hline \multicolumn{2}{|c|}{ Meteorological factors } & Correlation co-efficient & Regression equation \\
\hline \multirow{3}{*}{ Temperature $\left({ }^{\circ} \mathrm{C}\right)$} & Maximum & +0.7376 & $\mathrm{y}=2.02+44.36$ \\
\cline { 2 - 4 } & Minimum & +0.7596 & $\mathrm{y}=1.41 \mathrm{x}+13.43$ \\
\cline { 2 - 4 } & Gradient & -0.4789 & $\mathrm{y}=1.66 \mathrm{x}-29.56$ \\
\hline \multirow{2}{*}{$\begin{array}{c}\text { Relative Humidity } \\
(\%)\end{array}$} & Maximum & -0.4249 & $\mathrm{y}=1.01 \mathrm{x}-107.88$ \\
\cline { 2 - 4 } & Minimum & +0.4366 & $\mathrm{y}=0.36+11.46$ \\
\cline { 2 - 4 } & Gradient & -0.5481 & $\mathrm{y}=0.422 \mathrm{x}-23.49$ \\
\hline \multicolumn{2}{|c|}{ Rainfall (mm.) } & +0.4367 & $\mathrm{y}=0.04 \mathrm{x}+11.20$ \\
\hline \multicolumn{2}{|c|}{ Sunshine hour per day } & -0.3123 & $\mathrm{y}=1.35 \mathrm{x}-21.57$ \\
\hline
\end{tabular}

The positive impact of rainfall on the fly incidence was in corroboration with the earlier findings of Mahmood et al.,(2002). The possible reason of revealing positive correlation of minimum humidity with fly incidence may be due to higher rainfall that indirectly leads to increase in relative humidity of the environment. Sunshine hour correlated negatively with the fly incidence which indicated that sunnier the day, less was the fly activity. It may be like that during sunny days the flies prefer to congregate below the leaf surface or under the shade of vegetation. The fly population round the year as influenced by rainfall and sunshine hour per day has been presented in Fig-3. Impact of daily total sunshine hour on the incidence of fly was represented in the Fig-4. 
The Effect of Meteorological Factors.....

Melon fly populations round the year fluctuate much from time to time. Higher population density was recorded during the hot months while low or very low during the cooler months. So, it is very clear that the crops to be grown during cool months i.e. in 'rabi' season so as to avoid the infestation of this dreaded pest. Chemical means of pest management is not desirable because the crop is used as vegetable. In addition to that the avoiding principle of Integrated Pest Management is also environment friendly and economically viable. But it is also true that the cucurbits are basically summer season crop and thrive well in hot and humid seasons giving optimum yield. So, considering both the aspects, it may wisely be suggested that photo and thermo-insensitive varieties of the crops need to be developed that would perform better round the year and intensification of cropping pattern towards cooler months. This might help much to avoid infestation of the dreaded pest, the melon fruit fly.

Acknowledgements: The authors are thankful to Dr. S. K. Ghosh, Head, Department of Agricultural Entomology, Uttar Banga Krishi Viswavidyalaya, Pundibari, Cooch Behar, West Bengal, India for providing necessary facilities for conducting the investigation works and valuable suggestions during the course of investigation.

\section{REFERENCES}

Banerji, R, Sahoo, SK; Das, SK and Jha, S (2005). Studies on incidence of melon fly, Bactrocera cucurbitae (Coq.) in relation to weather parameters on bittergourd in new alluvial zone of West Bengal. Journal of Entomological Research 29(3): 179-182.

Bharathi, TE, Sathiyanandam, VKR and David, PMM (2004). Attractiveness of some food baits to the melon fruit fly, Bactrocera cucurbitae (Coq.) (Diptera: Tephritidae) International Journal of Tropical Insect Science 24(2): 125134.

Bot, J (1965). Census of a Dacinae population (Diptera: Tephritidae). J. Ent. Soc. S. Africa, 28(2):166-170.

Dhillon, MK, Singh, R; Naresh, JS and Sharma, HC (2005). The melon fly, Bactrocera cucurbitae: A review of its biology and management. Journal of Insect Science 5: 40.

Gupta, D and Bhatia, R (2000). Population fluctuation of Bactrocera spp. in submountainous mango and guava orchards. Journal of Applied Horticulture 1(2): 101-102.
Hasyim, A, Muryati and de Kogel, WJ (2008). Population fluctuation of the adult males of the fruit fly, Bactrocera tau Walker (Diptera: Tephritidae) in passion fruit orchards in relation to abiotic factors and sanitation. Indonesian Journal of Agricultural Science 9(1):29-33.

Jang, EB and Light, DM (1996). Olfactory semiochemicals of tephritids, In: Fruit Fly Pest: A world assessment of their biology and Management (Edited by B. A. Mc Pheron and G. J. Steck), St. Lucie Press, Florida, pp. 73-90.

Kapoor, VC (1993). Indian Fruit Flies (Insecta: Diptera: Tephritidae) Oxford and IBH Publishing Co. Pvt. Ltd., New Delhi, pp. 228.

Liu, YC and Lin, JS (1993). The response of melon fly, Dacus cucurbitae Coq. to the attraction of 10\% MC. Plant Protection Bulletin, Taipei 35:79-88.

Lui, YC and Yeh, CC (1982). Population fluctuation of the oriental fruit fly, Dacus dorsalis Hendel. in sterile fly release and control area. Chinese Journal of Entomology 2:57-70.

Mahmood, K and Mishkatullah (2007). Population dynamics of three species of Bactrocera (Diptera: Tephritidae: Dacinae) in BARI, Chakwal (Punjab). Pakistan Journal of Zoology 39(2):123126.

Mahmood, T, Hussain, SI; Khokhar, KM and Hidayatullah, MA (2002). Studies on methyl eugenol as a sex attractant for fruit fly, Dacus zonatus (Saund) in relation to abiotic factors in peach orchard. Asian Journal of Plant Sciences 4: 401-402.

Matanmi, BA (1979). A biology of Tephritid fruit flies (Diptera: Tephritidae) attacking cucurbits at Nigeria. Nigerian J. Enotomol. 1(2):153-159.

Nair, MRGK (1995). Insects and mites of crops in India, Indian Council of Agricultural Research (ICAR), New Delhi, pp-165-166.

Patel, RK and Patel, CB (1996). Influence of weather parameters on incidence of fruit fly, Dacus ciliatus on little gourd. Indian Journal of Entomology, 58(3):239-244.

Patnaik, HP, Sarangi, PK and Mahapatra, P (2004). Studies on the incidence of fruit flies and jassids on summer bittergourd and their control. Orissa Journal of Horticulture, 32(2):87-90. 
The Effect of Meteorological Factors.....

Pawar, DB, Mote, UN and Lawande KE (1991). Monitoring of fruit fly population in bittergourd crop with the help of lure trap. Journal of Research, Maharastra Agricultural University 16:281.

Ripley, LB and Hepburn, CA (1935). Olfactory attractant for male fruit flies. Dept. Agri. Union of South Africa Entomol. Memoir, 9:3-17.

Shukla, RP and Prasad, VG (1985). Population fluctuation of the oriental fruit fly, Dacus dorsalis Hendel in relation to host and abiotic factors. Tropical Pest Management, 31:273-275.

Su, CY (1984). The study on the relationship between seasonal succession of male adult of melon fly,
D. cucurbitae and the meteorological factors. J. Agric. For., 32:105-109.

Tanaka, AHS and Nagashimad, Y (1987). Fluctuation in number of melon fly male, Dacus cucurbitae (Coq.) caught in traps at different habitats of Kikai. Proc. of Association for Plant Protection of Kyushu, Japan 24:122-124.

Virakthamath, S and Babu, KS (2004). Species composition and population dynamics of fruit flies (Diptera: Tephritidae) on guava. South Indian Horticulture, 52(1/6): 317-323.

Zaman, M (1995). Assesment of male population of the fruit flies through kairomone baited traps and the association of abundance levels with the environmental factors. Sarhad Journal of Agriculture 11: 657-670. 